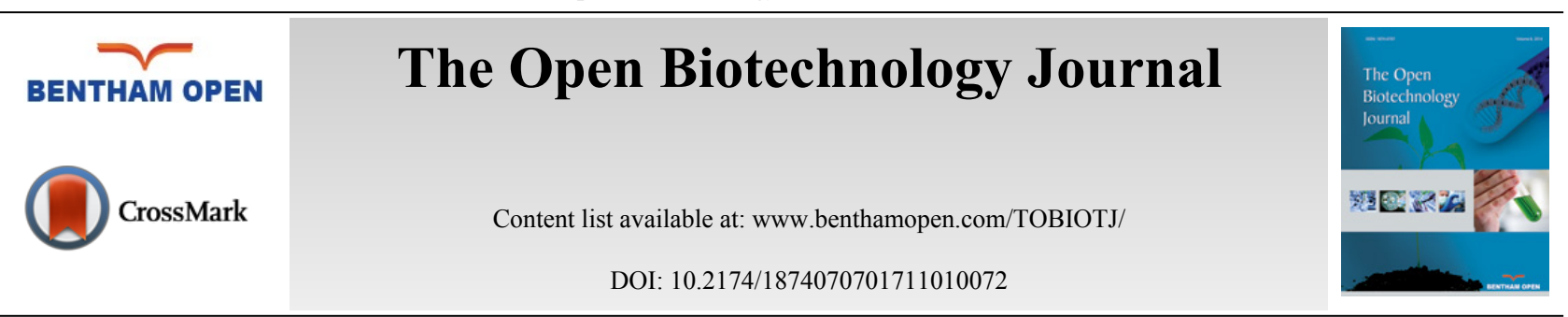

RESEARCH ARTICLE

\title{
Effects of the Addition of Sodium Chloride to a Tetrameric Protein in Water Solution During Exposure to High Frequency Electromagnetic Field
}

\author{
Emanuele Calabrò $^{1,5, *}$ and Salvatore Magazù ${ }^{1,2,3,4}$ \\ ${ }^{I}$ Department of Mathematical and Informatics Sciences, Physics Sciences and Earth Sciences of Messina University, \\ Viale Ferdinando Stagno D' Alcontres 31, 98166 Messina, Italy. \\ ${ }^{2}$ Le Studium, Loire Valley Institute for Advanced Studies, Orléans \& Tours, France. \\ ${ }^{3}$ Centre de Biophysique Moleculaire (CBM)-CNRS UPR 4301 du CNRS, rue Charles Sadron, 45071 Orleans CEDEX 2 \\ France; Laboratoire Interfaces, Confinement, Matériaux et Nanostructures (ICMN) - UMR 7374 CNRS - Université \\ d'Orléans, $1 b$ rue de la Férollerie, CS 40059, 45071 Orléans cedex 2, France. \\ ${ }^{4}$ Istituto Nazionale di Alta Matematica "F. Severi" - INDAM - Gruppo Nazionale per la Fisica Matematica -GNFM \\ 'Industrial Technical Institute "Verona Trento-Marconi", 98123 Messina, Italy.
}

Received: March 07, 2017

Revised: June 01, 2017

Accepted: June 01, 2017

\section{Abstract:}

Background:

Previous studies have shown that exposure to high frequency electromagnetic fields induces alterations in simple organic systems such as proteins in bidistilled water solution.

\section{Objective:}

The aim of this study was to test the shielding action of sodium chloride in bidistilled water solution against exposure to a high frequency electromagnetic field, in order to evaluate if the addition of $\mathrm{NaCl}$ in proteins aqueous solution can be considered a valuable bioprotector against electromagnetic fields.

\section{Method:}

Samples of $250 \mu \mathrm{l}$ of different hemoglobin aqueous solutions, in the absence or presence of sodium-chloride, were exposed for 3 hours to an electromagnetic field at $1750 \mathrm{MHz}$ at a power density around $1 \mathrm{~W} / \mathrm{m}^{2}$ emitted by an operational mobile phone. Fourier Transform Infrared Spectroscopy was used to study the effects of exposure on the secondary structure of hemoglobin also in the presence of sodium-chloride.

\section{Results:}

Spectral analysis evidenced that significant increase in intensity of the Amide I and II vibration bands in hemoglobin bidistilled water solution occurred after exposure to the electromagnetic field. This result can be due to the increase of dipole moment of the protein due to the alignment of $\alpha$-helix towards the direction of the field. In contrast, no appreciable change was observed in hemoglobin in sodium-chloride water solution after exposure.

\footnotetext{
* Address correspondence to this author at the Department of Mathematics and Informatics Sciences, Physics Sciences and Earth Sciences, University of Messina, Viale D’Alcontres, 31 - I-98166 Messina, Italy; Tel: +390906765019; E-mail: e.calabro@yahoo.com
} 


\section{Conclusion:}

This protective effect of sodium-chloride can be explained by the orientation of water molecules due to the strong electric field around each ion that reduces the possibility of rotation of the protein in response to an applied electromagnetic field.

Keywords: Electromagnetic field, Hemoglobin, Sodium-chloride, Amide I, FTIR spectroscopy, Bidistilled water solution.

\section{INTRODUCTION}

Previous studies on the effects of high frequency electromagnetic fields (HF-EMFs) on human health have been carried up to now due to the enormous achievement of radio and TV transmitter stations, home wireless devices and mobile telephony, in order to clarify if exposure to these devices can affect human health.

Some epidemiological studies have evidenced a possible correlation between an increase of risk of cancer and exposure to HF-EMFs [1, 2]. In addition, an assessment which was published in 2007 regarding the effects of mobile phone radiation on human health concluded that further study on the effects of radio-frequency (RF) and microwave (MW) radiations on livings are needed [3].

In vitro studies showed that RF-MWs can be carcinogens [4] and can induce DNA damage and chromosomes aberrations [5 - 7]. Furthermore, it was observed that mobile phone MWs alter blood-brain barrier permeability [8], produce oxidative damage in brains tissues [9] and induce increasing of heat shock proteins levels in neuronal-like cells [10].

In view of these results, national radiation advisory authorities have suggested to carry out measurements in order to minimize exposure of humans and exposure limits to electromagnetic fields have been recommended by the International Commission on Non-Ionizing Radiation Protection (I.C.N.I.R.P.) [11].

Nevertheless, previous studies have largely demonstrated that also exposure to HF-EMF within those recommended exposure limits induces alterations in simple organic systems such as cells and proteins [10, 12 - 18]. Following these results, the effects of the use of disaccharides as bioprotectors against EMFs were investigated [17, 19 - 21].

In this study, the shielding action of sodium chloride $(\mathrm{NaCl})$ against exposure of hemoglobin $(\mathrm{Hb})$ to HF-EMF was shown.

The main reason of this choice depends on the circumstance that proteins are fundamentals in organic metabolism of livings. In particular $\mathrm{Hb}$ is a tetrameric protein, i.e. it has a quaternary structure with four identical subunits that are linked by non-covalent interactions such as hydrogen bonding and electrostatic interactions. This delicate equilibrium can be changed by exposure to HF-EMFs, such as it was shown in previous research $[12,14,16,17]$.

$\mathrm{NaCl}$ is a molecule with sodium and chloride replacement capabilities, whose presence in the human body is fundamental for many physiological functions such as intracellular osmolarity, nerve conduction and muscle contraction. Furthermore, "normal saline" $(\mathrm{NaCl} 0.9 \%)$ is the most frequently prescribed balanced salt solution in clinical practice, which deserve consideration as infusates of first choice $[22,23]$. Therefore, the use of $\mathrm{NaCl}$ as a bioprotector against HF-EMFs would not contravene any contraindications.

To this aim, the effects of exposure on the secondary structure of $\mathrm{Hb}$ bidistilled water solution, also in the presence of $\mathrm{NaCl}$, were studied by means of Fourier Transform Infrared (FTIR) spectroscopy. Indeed, previous research has shown that FTIR spectroscopy is a valuable tool for analyzing protein structure in $\mathrm{H}_{2} \mathrm{O}$ or $\mathrm{D}_{2} \mathrm{O}$ solution [24 - 26].

\section{MATERIALS AND METHODS}

\subsection{Haemoglobin Samples}

Samples of blood were obtained by venipuncture from healthy human subjects that were recruited for this study. Blood samples were treated as described in $[19,20]$ in order to obtain $\mathrm{Hb}$ solution.

Twenty samples of $\mathrm{Hb}$ solutions were prepared at $150 \mathrm{mg} / \mathrm{ml}$ concentration in bidistilled water and $50 \mathrm{mg} / \mathrm{ml}$ sodium chloride was added to an half of these samples.

\subsection{Experimental Design}

The experimental setup consisted of an operational mobile phone, model Samsung GT-E1270, with Vodafone as the signal provider and the micro-cell was located in the area of the Department of Mathematics and Informatics Sciences, 
Physics Sciences and Earth Sciences, University of Messina (Italy).

This exposure source provided MWs at $1750 \mathrm{MHz}$ frequency at the average power density of $950 \mathrm{~mW} / \mathrm{m}^{2}$. Each sample of $250 \mu \mathrm{L}$ of $\mathrm{Hb}$ solutions, in the absence and in presence of $\mathrm{NaCl}$, was placed at a distance of three centimeters from the operational mobile phone. Analogue unexposed samples at the same room temperature were located away from the exposure system and used as the control. The average intensity of the power density was monitored by a SRM-3000 device of Narda Safety Test Solutions. It was linked through a cable to a Narda three axis antenna covering the frequency range from $75 \mathrm{MHz}$ to $3 \mathrm{GHz}$. A preliminary analysis was carried out in order to detect the MWs frequencies values impinging the three axis antenna as accurately described in [14 - 16]. Moreover, time analysis mode was continuously used in order to monitor the power density emitted by the operational mobile phone.

\subsection{Infrared Spectroscopy}

FTIR spectroscopy measurements were carried out using a spectrometer Vertex 80v of Bruker Optics.

$\mathrm{Hb}$ aqueous solution samples $(150 \mathrm{mg} / \mathrm{ml})$, in absence or presence of sodium-chloride at $50 \mathrm{mg} / \mathrm{ml}$ concentration, were placed between a pair of $\mathrm{CaF}_{2}$ windows separated with a $25 \mu \mathrm{m}$ Teflon spacer. For each spectrum 64 interferograms were collected with a spectral resolution of $4 \mathrm{~cm}^{-1}$.

IR spectrum of water solution was subtracted from the spectra of $\mathrm{Hb}$ solutions at the corresponding temperature. Measurements were performed under vacuum in order to eliminate minor spectral contributions of residual water vapor. In addition, smoothing correction for atmospheric water background and baseline correction for exposed and unexposed $\mathrm{Hb}$ solutions were performed.

Furthermore, vector normalization was used. This procedure calculates the average value of the spectrum and subtracts the mid-spectrum from the spectrum decreasing. Thus, the sum of the squares of all values was calculated and the spectrum was divided by the square root of this sum.

Finally, interactive baseline rubber band correction was used. This procedure uses a rubber band which is stretched from one spectrum to the other. The band is pressed onto the spectrum from the bottom up with varying intensity [27]. This algorithm performs iteratively, which depends on the number of iterations of the procedure so that the resulting spectrum is the original spectrum subtracted by the baselines points manually set and a subsequent concave rubber band correction. The value of $n=85$ baseline points and 50 iterations were used.

In order to enhance fine spectral features, Fourier self-deconvolution (FSD) analyses of infrared spectra were performed, because the interpretation of spectral data is often impeded by the effect of overlapping bands. Indeed, deconvolution is the process of compensating for the intrinsic line widths of bands in order to resolve overlapping bands [28]. This technique is based on the assumption that a spectrum of single narrow bands can be broadened in the liquid or solid state so that it cannot be distinguished in the amide envelope. Hence, a curve fitting procedure can be applied to estimate quantitatively the area of each component representing a type of secondary structure. This technique can be successfully applied to the spectra of solutions, where vibration bands are widened in the liquid or solid state because of intermolecular interactions and cannot be distinguished in the amide envelope. Spectral ranges comprising broad and overlapping lines can thus be separated into sharp single lines [29].

\section{RESULTS AND DISCUSSION}

FTIR spectroscopy analysis was used to investigate structural changes of vibration bands of human Hb aqueous solutions in the absence or presence of $\mathrm{NaCl}$ induced by exposure to $\mathrm{MWs}$ at $1750 \mathrm{MHz}$ at $950 \mathrm{~mW} / \mathrm{m}^{2}$.

Samples of $250 \mu \mathrm{l}$ of $\mathrm{Hb}$ solutions were exposed for $3 \mathrm{~h}$ following the protocol described in the preceding section. Typical transmittance spectra in the mid-infrared region from 3500 to $1350 \mathrm{~cm}^{-1}$ of $\mathrm{Hb}$ in bidistilled water and $\mathrm{NaCl}$ solutions are represented in Fig. (1) and Fig. (2), respectively.

An intense Amide I vibration band centered at $1654 \mathrm{~cm}^{-1}$ and the Amide II band at $1545 \mathrm{~cm}^{-1}$, can be observed in the exposed and unexposed spectra of both solutions. These bands correspond to the $\alpha$-helix structure, mainly due to $\mathrm{C}=\mathrm{O}$ stretching vibration and $\mathrm{N}-\mathrm{H}$ bending mode, and to coupling of the $\mathrm{N}-\mathrm{H}$ bending and C-N stretching modes, respectively [30 - 33]. 


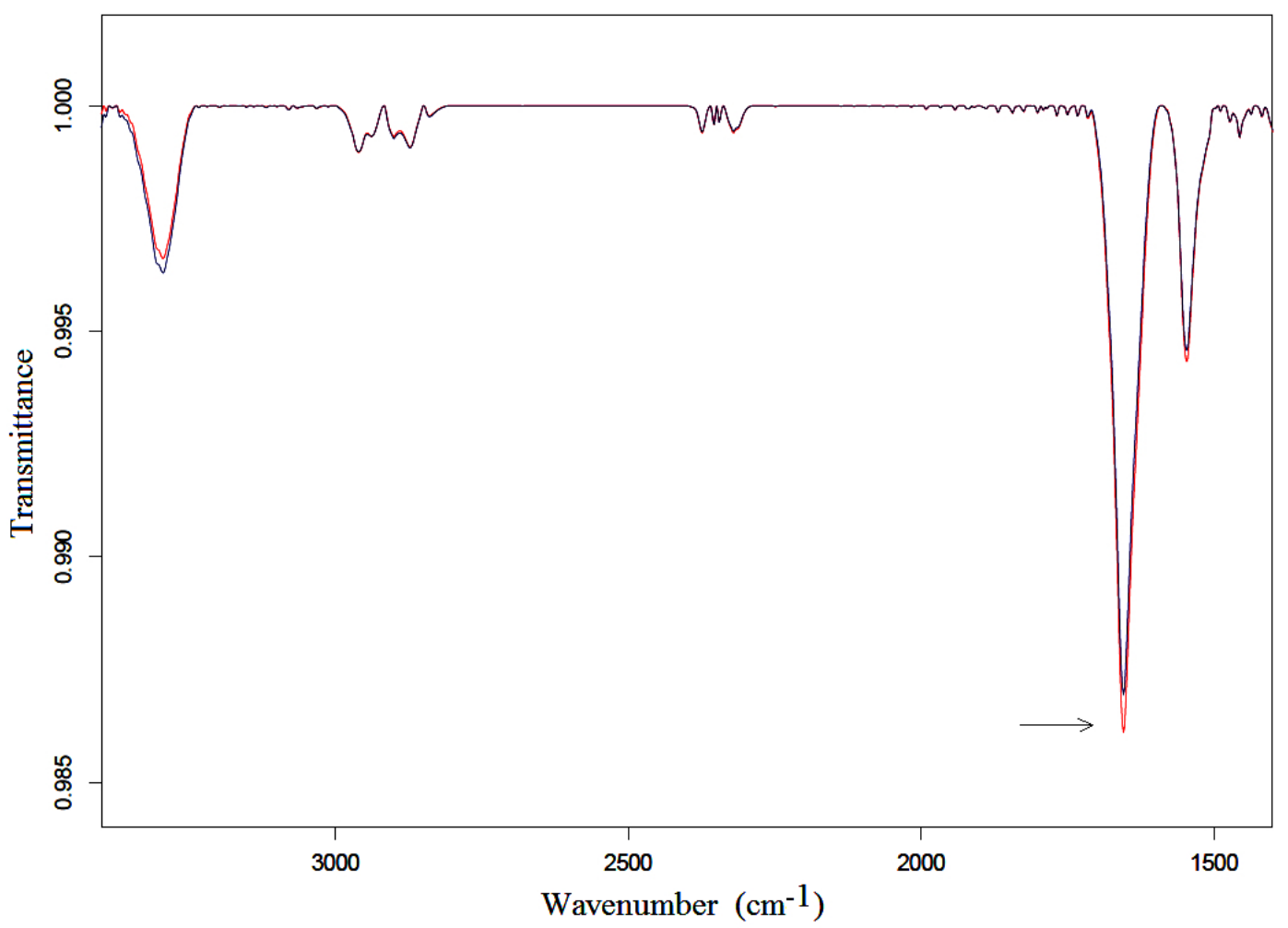

Fig. (1). Representative IR spectra from 3500 to $1350 \mathrm{~cm}^{-1}$ of hemoglobin in bidistilled water solution after $3 \mathrm{~h}$ of exposure to 1750 MHz mobile phone MWs at the power density of $950 \mathrm{~mW} / \mathrm{m}^{2}$ (red line refers to exposed sample). Significant increase in intensity of Amide I vibration band $(\mathrm{p}<0.05)$ is indicated by an arrow.

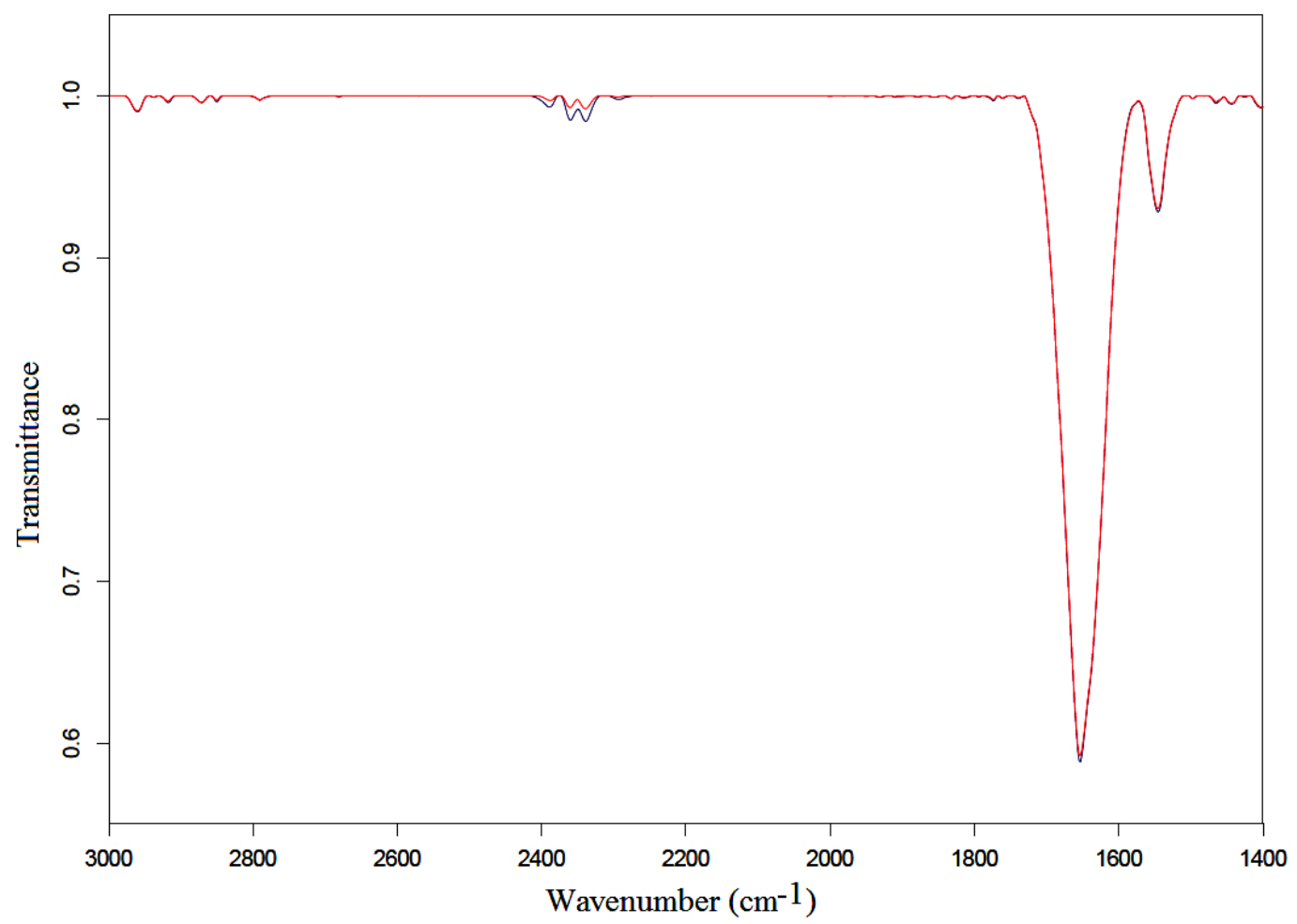

Fig. (2). Representative IR spectra from 3500 to $1350 \mathrm{~cm}^{-1}$ of hemoglobin in $\mathrm{NaCl}$ water solution after $3 \mathrm{~h}$ of exposure to $1750 \mathrm{MHz}$ mobile phone MWs at the power density of $950 \mathrm{~mW} / \mathrm{m}^{2}$ (red line refers to exposed sample). No appreciable change was observed after exposure of hemoglobin samples in $\mathrm{NaCl}$ water solution. 
Also, the Amide A band, centered at $3293 \mathrm{~cm}^{-1}$ appeared in the spectra. It derives from an overtone of Amide II or a combination of Amide I and Amide II that interacts with the strong NH s fundamental through a cubic anharmonic potential, acquiring enough intensity to be observable through a Fermi resonance [34, 35].

Finally, low intensities vibration bands at 2961, 2871, 2925, $2853 \mathrm{~cm}^{-1}$ can be observed in the spectra; these bands originate, from the asymmetric stretching ${ }^{\text {as }} \mathrm{CH}_{3}$, the symmetric stretching ${ }^{\mathrm{s}} \mathrm{CH}_{3}$ vibrations of $\mathrm{CH}_{3}$ methyl group, the asymmetric stretching ${ }^{\text {as }} \mathrm{CH}_{2}$ and the symmetric stretching ${ }^{\mathrm{s}} \mathrm{CH}_{2}$ of the methylene group, respectively [36 - 38].

Amide I and Amide II vibration bands in $\mathrm{Hb}$ in bidistilled water solution increased in intensity after exposure, as can be observed in Fig. (1), whereas no appreciable change was detected after exposure in the exposed spectra of $\mathrm{Hb}$ in $\mathrm{NaCl}$ bidistilled water solution (Fig. 2).

Moreover, Fourier self deconvolution (FSD) analysis was applied to acquired spectra in order to highlight alterations occurred in the Amide I and II regions. In this study, FSD analysis was applied to exposed and unexposed spectra using a Lorentzian shape, with bandwidth $=23.07$, deconvolution factor $=2.5$, smoothing 5 points.

A representative FSD analysis of $\mathrm{Hb}$ in bidistilled water solution, which was calculated from 1700 to $1500 \mathrm{~cm}^{-1}$, is represented in Fig. (3). Also this analysis confirmed that Amide I and Amide II vibration bands increased after exposure to MWs. In particular, applying t-test student to a set of twelve spectra, calculating the integrated area of exposed and unexposed vibration bands, it was found that the increasing in intensity of the Amide I band was significant with $p<$ 0.05 .

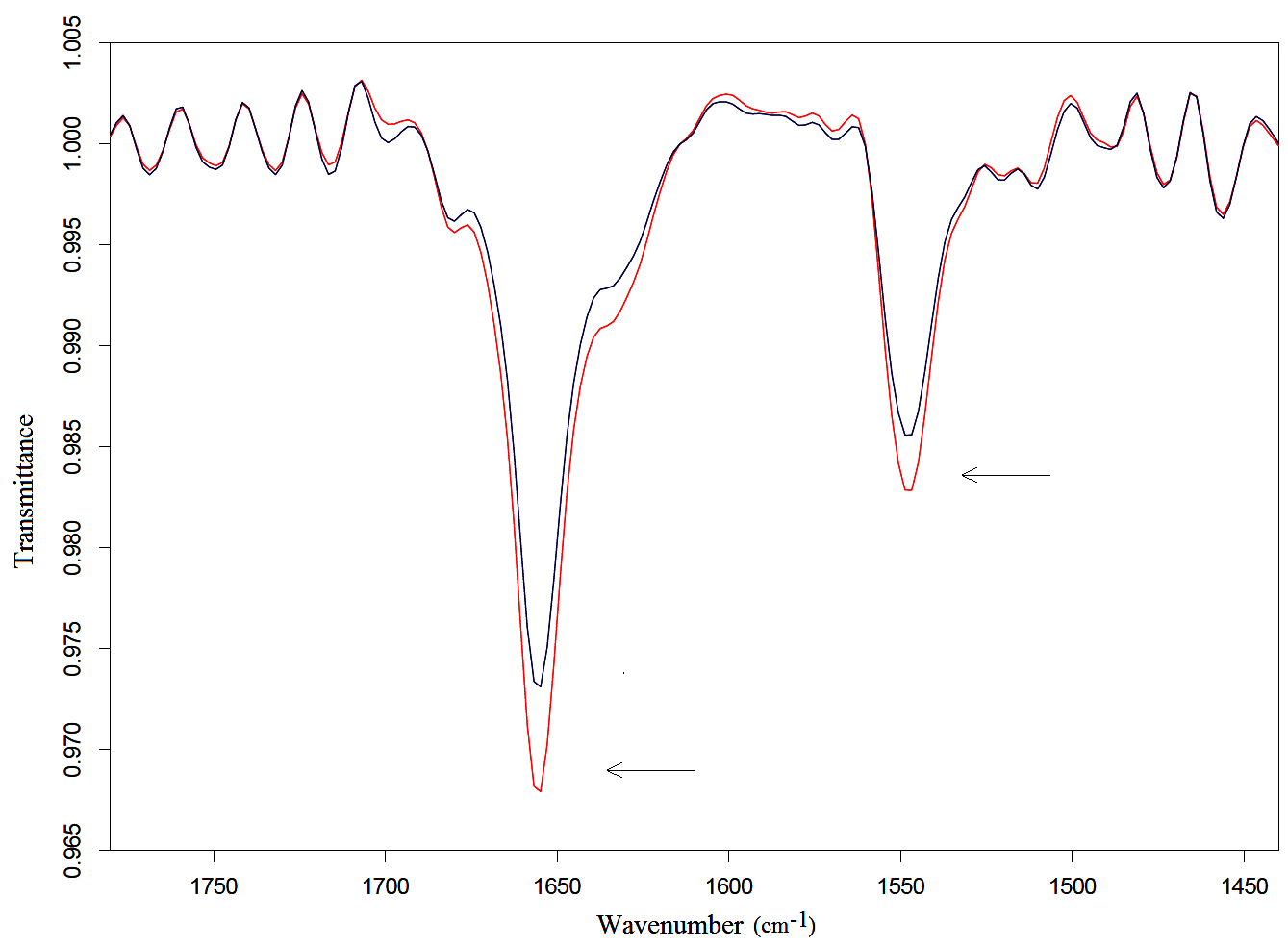

Fig. (3). FSD representative spectra of Amide I and Amide II regions of hemoglobin in bidistilled water solution after $3 \mathrm{~h}$ of exposure to $1750 \mathrm{MHz}$ mobile phone MWs at the power density of $950 \mathrm{~mW} / \mathrm{m}^{2}$ (red line refers to exposed sample). FSD analysis evidenced that both Amide I and Amide II vibration bands (indicated by arrows) increased significantly after exposure of Hemoglobin in bidistilled water solution $(\mathrm{p}<0.05)$.

In contrast, no significant alteration occurred after exposure of $\mathrm{Hb}$ in $\mathrm{NaCl}$ bidistilled water solution, as represented in Fig. (4). These results can be explained as follows. 


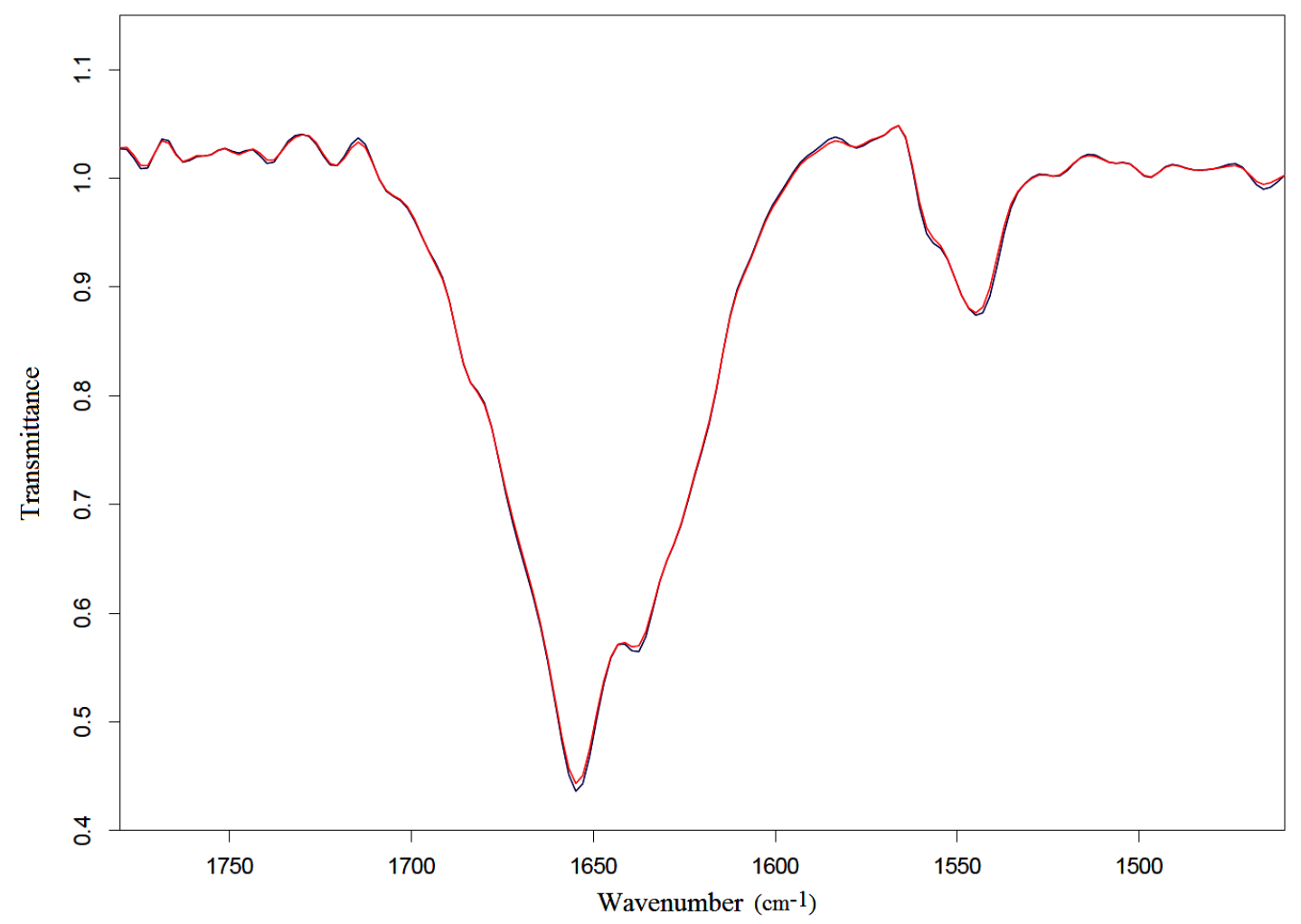

Fig. (4). FSD representative spectra of Amide I and Amide II regions of hemoglobin in $\mathrm{NaCl}$ water solution after $3 \mathrm{~h}$ of exposure to $1750 \mathrm{MHz}$ mobile phone MWs at the power density of $950 \mathrm{~mW} / \mathrm{m}^{2}$ (red line refers to exposed sample). No appreciable change was observed in this analysis after exposure of hemoglobin samples in $\mathrm{NaCl}$ water solution.

The $\mathrm{C}=\mathrm{O}$ stretch is particularly intense due to its large dipole moment, giving rise to the Amide I band which increases during the stretch, depending on change in the dipole moment.

Indeed, the dipole moment of the single peptide units and their arrangement in helices produces a large net dipole moment from one end of the helix to the other, whose amount depends on the type of protein and is typically of the order of several hundred Debye.

Hence, because a helix possesses a large dipole moment, it will attempt to align itself with the EMF by a rotation. The dipole can rotate in phase with the oscillating EMF under low frequency irradiation, but under HF-EMF the dipole cannot follow the oscillating field. As a result, each $\alpha$-helix of the protein will place itself at an average position towards the direction of the applied field, inducing an increase of total amount of dipole moment and the consequent increasing in intensity of the Amide I and II vibrations. Furthermore, the absence of significant change in the secondary structure of $\mathrm{Hb}$ in $\mathrm{NaCl}$ bidistilled water solution can be explained, as well.

In fact, when the $\mathrm{NaCl}$ ions are dissolved in water, the permittivity of water is reduced and polar water molecules are replaced by charged but non-polar ionic particles, producing the formation of a strong electric field around each ion [39]. This field generated by each ion dissolved in water induces random orientation of water molecules. In addition, each $\alpha$-helix structure of the protein is linked to water molecules by hydrogen bonding. As a result, the way in which the $\alpha$-helices of the protein can rotate in a $\mathrm{NaCl}$ water solution should be reduced in response to the applied HF-EMF. In view of these facts, the addition of $\mathrm{NaCl}$ in proteins aqueous solution can be considered a valuable bioprotector against HF-EMFs.

\section{CONCLUSION}

FTIR spectroscopy was used to study the effects of $1750 \mathrm{MHz}$ mobile phone MWs at the power density around 1 $\mathrm{W} / \mathrm{m}^{2}$ on the secondary structure of hemoglobin in bidistilled water solution, in the absence or presence of sodiumchloride.

FTIR spectroscopy and FSD analysis evidenced significant increase in intensity of the Amide I vibration band of 
hemoglobin after $3 \mathrm{~h}$ of exposure. This result can be explained assuming that the interaction between the $\alpha$-helix structure of the protein and the applied HF-EMF induces the alignment of the $\alpha$-helices with the direction of the field increasing the total amount of the dipole moment and the consequent increases in intensity of the Amide I and II vibration bands, particularly of the Amide I, whose major contribution derives from the $\alpha$-helix content.

In contrast, no significant change was observed after $3 \mathrm{~h}$ of exposure of hemoglobin in sodium-chloride aqueous solutions, because of the replacing polar water molecules by charged but non-polar ionic particles, impeding the alignment of the $\alpha$-helices towards the direction of the field.

In view of these results, we can assume that the addition of sodium chloride in proteins in bidistilled water solution induces a shielding action against exposure to high frequency electromagnetic fields, so that it can be considered a valuable bioprotector against radio frequencies and microwaves emitted by electronic devices usually used by humans.

\section{ETHICS APPROVAL AND CONSENT TO PARTICIPATE}

Not applicable.

\section{HUMAN AND ANIMAL RIGHTS}

No Animals/Humans were used for studies that are base of this research.

\section{CONSENT FOR PUBLICATION}

Not applicable.

\section{CONFLICT OF INTEREST}

The author (editor) declares no conflict of interest, financial or otherwise.

\section{ACKNOWLEDGEMENTS}

Declared None.

\section{REFERENCES}

[1] Electromagnetic fields (300 Hz to $300 \mathrm{GHz})$ environmental health criteria, No: 137. Occup Environ Med 1994; $51(10)$ : 720. [http://dx.doi.org/10.1136/oem.51.10.720-a]

[2] Repacholi MH, Basten A, Gebski V, Noonan D, Finnie J, Harris AW. Lymphomas in E mu-Pim1 transgenic mice exposed to pulsed 900 MHZ electromagnetic fields. Radiat Res 1997; 147(5): 631-40. [http://dx.doi.org/10.2307/3579630] [PMID: 9146709]

[3] Possible effects of electromagnetic fields (EMF) on human health. Scientific Committee on Emerging and Newly Identified Health Risks on Human Health 2006; pp. 1-58.

[4] Balcer-Kubiczek EK, Harrison GH. Neoplastic transformation of C3H/10T1/2 cells following exposure to 120-Hz modulated 2.45-GHz microwaves and phorbol ester tumor promoter. Radiat Res 1991; 126(1): 65-72. [http://dx.doi.org/10.2307/3578172] [PMID: 2020740]

[5] Diem E, Schwarz C, Adlkofer F, Jahn O, Rüdiger H. Non-thermal DNA breakage by mobile-phone radiation (1800 MHz) in human fibroblasts and in transformed GFSH-R17 rat granulosa cells in vitro. Mutat Res 2005; 583(2): 178-83. [http://dx.doi.org/10.1016/j.mrgentox.2005.03.006] [PMID: 15869902]

[6] Garaj-Vrhovac V, Horvat D, Koren Z. The effect of microwave radiation on the cell genome. Mutat Res 1990; 243(2): 87-93. [http://dx.doi.org/10.1016/0165-7992(90)90028-I] [PMID: 2304485]

[7] Tice RR, Hook GG, Donner M, McRee DI, Guy AW. Genotoxicity of radiofrequency signals. I. Investigation of DNA damage and micronuclei induction in cultured human blood cells. Bioelectromagnetics 2002; 23(2): 113-26. [http://dx.doi.org/10.1002/bem.104] [PMID: 11835258]

[8] Fritze K, Sommer C, Schmitz B, et al. Effect of global system for mobile communication (GSM) microwave exposure on blood-brain barrier permeability in rat. Acta Neuropathol 1997; 94(5): 465-70. [http://dx.doi.org/10.1007/s004010050734] [PMID: 9386779]

[9] Salford LG, Brun AE, Eberhardt JL, Malmgren L, Persson BR. Nerve cell damage in mammalian brain after exposure to microwaves from GSM mobile phones. Environ Health Perspect 2003; 111(7): 881-3. [http://dx.doi.org/10.1289/ehp.6039] [PMID: 12782486]

[10] Calabrò E, Condello S, Currò M, et al. Modulation of HSP response in SH-SY5Y cells following exposure to microwaves of a mobile phone. World J Biol Chem 2012; 3(2): 34-40. [http://dx.doi.org/10.4331/wjbc.v3.i2.34] [PMID: 22371824] 
[11] Guidelines for limiting exposure to time-varying electric, magnetic, and electromagnetic fields (up to $300 \mathrm{GHz}$ ). Health Phys 1998; 74(4): 494-522.

[PMID: 9525427]

[12] Calabrò E, Magazù S. Inspections of mobile phone microwaves effects on proteins secondary structure by means of fourier transform infrared spectroscopy. JEMAA 2010; 2: 607-17. [http://dx.doi.org/10.4236/jemaa.2010.211080]

[13] Calabrò E, Magazù S. Unfolding and aggregation of myoglobin can be induced by three hours exposure to mobile phone microwaves: a FTIR spectroscopy study. Spectrosc Lett 2013; 46(8): 583-9. [http://dx.doi.org/10.1080/00387010.2013.771274]

[14] Calabrò E, Magazù S. Fourier -Self -Deconvolution analysis of $\beta$-sheet contents in the Amide I region of hemoglobin aqueous solutions under exposure to $900 \mathrm{MHz}$ microwaves and bioprotective effectiveness of sugars and salt solutions. Spectrosc Lett 2015; 48(10): 741-7. [http://dx.doi.org/10.1080/00387010.2015.1011278]

[15] Calabrò E, Magazù S. Transition from $\alpha$-helix to $\beta$-sheet structures occurs in myoglobin in deuterium oxide solution under exposure to microwaves PD 044, 29th Annual Symposium of the Protein Society. July 22-25, 2015; Barcelona, Spain.

[16] Calabrò E, Magazù S. Parallel $\beta$-sheet vibration band increases with proteins dipole moment under exposure to $1765 \mathrm{MHz}$ microwaves. Bioelectromagnetics 2016; 37(2): 99-107. [PMID: 26833949]

[17] Magazù S, Calabrò E, Caccamo MT, Cannuli A. The shielding action of disaccharides for typical proteins in aqueous solution against static, $50 \mathrm{~Hz}$ and $1800 \mathrm{MHz}$ frequencies electromagnetic fields. Curr Chem Biol 2016; 10(1): 57-64 [http://dx.doi.org/10.2174/2212796810666160419153722]

[18] Calabrò E, Magazù S. Microwave radiation at $1800 \mathrm{MHz}$ induces increase of $\beta$-turn and $\beta$-sheet features in typical proteins, RAD 2016 Fourth International Conference on Radiation and Applications in Various Fields of Research. May 23-27, 2016; Niš.

[19] Magazù S, Calabrò E, Campo S. FTIR spectroscopy studies on the bioprotective effectiveness of trehalose on human hemoglobin aqueous solutions under $50 \mathrm{~Hz}$ electromagnetic field exposure. J Phys Chem B 2010; 114(37): 12144-9. [http://dx.doi.org/10.1021/jp104226p] [PMID: 20799749]

[20] Magazù S, Calabrò E, Campo S, Interdonato S. New insights into bioprotective effectiveness of disaccharides: an FTIR study of human haemoglobin aqueous solutions exposed to static magnetic fields. J Biol Phys 2012; 38(1): 61-74. [http://dx.doi.org/10.1007/s10867-010-9209-1] [PMID: 23277670]

[21] Calabrò E, Magazù S. Electromagnetic fields effects on the secondary structure of lysozyme and bioprotective effectiveness of trehalose. Advances in Physical Chemistry 2012; 2012 [http://dx.doi.org/10.1155/2012/970369]

[22] Stoneham MD, Hill EL. Variability in post-operative fluid and electrolyte prescription. Br J Clin Pract 1997; 51(2): 82-4. [PMID: 9158250]

[23] Severs D, Hoorn EJ, Rookmaaker MB. A critical appraisal of intravenous fluids: from the physiological basis to clinical evidence. Nephrol Dial Transplant 2015; 30(2): 178-87.

[http://dx.doi.org/10.1093/ndt/gfu005] [PMID: 24463187]

[24] Kong J, Yu S. Fourier transform infrared spectroscopic analysis of protein secondary structures. Acta Biochim Biophys Sin (Shanghai) 2007; 39(8): 549-59. [http://dx.doi.org/10.1111/j.1745-7270.2007.00320.x] [PMID: 17687489]

[25] Surewicz WK, Mantsch HH, Chapman D. Determination of protein secondary structure by Fourier transform infrared spectroscopy: a critical assessment. Biochemistry 1993; 32(2): 389-94. [http://dx.doi.org/10.1021/bi00053a001] [PMID: 8422346]

[26] Byler DM, Susi H. Examination of the secondary structure of proteins by deconvolved FTIR spectra. Biopolymers 1986; 25(3): 469-87. [http://dx.doi.org/10.1002/bip.360250307] [PMID: 3697478]

[27] Baker MJ, Trevisan J, Bassan P, et al. Using Fourier transform IR spectroscopy to analyze biological materials. Nat Protoc 2014; 9(8): 1771-91.

[http://dx.doi.org/10.1038/nprot.2014.110] [PMID: 24992094]

[28] Kauppinen JK, Moffatt DJ, Mantsch HH, Cameron DG. Fourier self-deconvolution-A method for resolving intrinsically overlapped bands. Appl Spectrosc 1981; 35: 271-6. [http://dx.doi.org/10.1366/0003702814732634]

[29] Bowley HJ, Collin SM, Gerrard DL, et al. The Fourier self-deconvolution of Raman spectra. Appl Spectrosc 1985; 39: 1004-9. [http://dx.doi.org/10.1366/0003702854249475]

[30] Yang W-J, Griffiths PR, Byler DM, Susi H. Protein conformation by infrared spectroscopy: resolution enhancement by Fourier self deconvolution. Appl Spectrosc 1985; 39(2): 282-7. [http://dx.doi.org/10.1366/0003702854248917]

[31] Krimm S, Bandekar J. Vibrational spectroscopy and conformation of peptides, polypeptides, and proteins. Adv Protein Chem 1986; 38: 181-364. 
[http://dx.doi.org/10.1016/S0065-3233(08)60528-8] [PMID: 3541539]

[32] Kato K, Matsui T, Tanaka S. Quantitative estimation of alpha-helix coil content in bovine serum albumin by Fourier transform-infrared spectroscopy. Appl Spectrosc 1987; 41(5): 861-5. [http://dx.doi.org/10.1366/0003702874448049]

[33] Sarver RW Jr, Krueger WC. Protein secondary structure from Fourier transform infrared spectroscopy: a data base analysis. Anal Biochem 1991; 194(1): 89-100.

[http://dx.doi.org/10.1016/0003-2697(91)90155-M] [PMID: 1867384]

[34] Miyazawa T. The characteristic band of secondary amides at $3100 \mathrm{~cm}^{-1}$. J Mol Spectrosc 1960; 4: 168-72. [http://dx.doi.org/10.1016/0022-2852(60)90076-X]

[35] Krimm S, Dwivedi AM. Vibrational analysis of peptides, polypeptides and proteins. XII. Fermi resonance analysis of the unperturbed ND stretching fundamental in polypeptides. J Raman Spectrose 1982; 12: 133-7. [http://dx.doi.org/10.1002/jrs.1250120209]

[36] Parker FS. Applications of infrared spectroscopy in biochemistry, biology and medicine. Plenum Press: New York 1971. [http://dx.doi.org/10.1007/978-1-4684-1872-9]

[37] Rigas B, Morgello S, Goldman IS, Wong PT. Human colorectal cancers display abnormal Fourier-transform infrared spectra. Proc Natl Acad Sci USA 1990; 87(20): 8140-4. [http://dx.doi.org/10.1073/pnas.87.20.8140] [PMID: 2236027]

[38] Dumas P, Miller L. The use of synchrotron infrared microspectroscopy in biological and biomedical investigations. Vib Spec 2003; 32: 3-21. [http://dx.doi.org/10.1016/S0924-2031(03)00043-2]

[39] Pethig R, Kell DB. The passive electrical properties of biological systems: their significance in physiology, biophysics and biotechnology. Phys Med Biol 1987; 32(8): 933-70.

[http://dx.doi.org/10.1088/0031-9155/32/8/001] [PMID: 3306721]

(C) 2017 Calabrò and Magazù.

This is an open access article licensed under the terms of the Creative Commons Attribution-Non-Commercial 4.0 International Public License (CC BY-NC 4.0) (https://creativecommons.org/licenses/by-nc/4.0/legalcode), which permits unrestricted, non-commercial use, distribution and reproduction in any medium, provided the work is properly cited. 